\title{
Impact of a Patient-Centered Behavioral Economics Intervention on Hypertension Control in a Highly Disadvantaged Population: a Randomized Trial
}

\author{
Martin F. Shapiro, MD, CM, PhD 1,2,3, Suzanne B. Shu, PhD ${ }^{1,4}$, Noah J. Goldstein, PhD ",4, \\ Ronald G. Victor, $M D^{1,5}$, Craig R. Fox, $P h D^{1,4}$, Chi-Hong Tseng, $P h D^{1}$, \\ Sitaram Vangala, $M A^{7}$, Braden K. Mogler, $M D^{7}$, Stewart B. Reed, $M D^{7}$, Estivali Villa, $B A^{7}$, \\ and José J. Escarce, MD, $P h D^{1,2}$
}

\begin{abstract}
'Department of Medicine, University of California, Los Angeles, Los Angeles, CA, USA; ${ }^{2}$ Department of Health Care Policy \& Management, University of California, Los Angeles, Los Angeles, CA, USA; ${ }^{3}$ Division of General Internal Medicine, Weill Cornell Medical College, New York, NY, USA; ${ }^{4}$ Anderson School of Management, University of California, Los Angeles, Los Angeles, CA, USA; ${ }^{5}$ Smidt Heart Institute, Cedars-Sinai Medical Center, Los Angeles, CA, USA.
\end{abstract}

BACKGROUND: Uncontrolled hypertension contributes to disparities in cardiovascular outcomes. Patient intervention strategies informed by behavioral economics and social psychology could improve blood pressure (BP) control in disadvantaged minority populations.

OBJECTIVE: To assess the impact on BP control of an intervention combining short-term financial incentives with promotion of intrinsic motivation among highly disadvantaged patients.

DESIGN: Randomized controlled trial.

PARTICIPANTS: Two hundred seven adults (98\% African American or Latino) aged 18 or older with uncontrolled hypertension attending Federally Qualified Health Centers.

INTERVENTION: Six-month intervention, combining financial incentives for measuring home $\mathrm{BP}$, recording medication use, BP improvement, and achieving target $\mathrm{BP}$ values with counseling linking hypertension control efforts to participants' personal reasons to stay healthy.

MAIN MEASURES: Primary outcomes: percentage achieving systolic BP (SBP) $<140 \mathrm{mmHg}$, percentage achieving diastolic $\mathrm{BP}$ (DBP) $<90 \mathrm{mmHg}$, and changes in SBP and DBP, all after 6 months. Priority secondary outcomes were $\mathrm{SBP}<140 \mathrm{mmHg}$, DBP < $90 \mathrm{mmHg}$, and BP change at 12 months, 6 months after the intervention ended.

KEY RESULTS: After 6 months, rates of achieving target $\mathrm{BP}$ values for intervention and control subjects respectively was $57.1 \%$ vs. $40.2 \%$ for SBP $<140 \mathrm{mmHg}$ (adjusted odds ratio (AOR) 2.53 (1.13-5.70)), 79.8\% vs $70.1 \%$ for DBP $<90 \mathrm{mmHg}$ (AOR $2.50(0.84-7.44)$ ), and 53.6\% vs $40.2 \%$ for achieving both targets (AOR 2.04 (0.92-4.52)). However, at 12 months, the groups did not differ significantly in these 3 measures: $39.5 \%$ vs $35.0 \%$ for SBP (AOR

Dr. Ronald G. Victor is deceased.

Electronic supplementary material The online version of this article (https://doi.org/10.1007/s11606-019-05269-z) contains supplementary material, which is available to authorized users.

Received November 21, 2018

Revised June 7, 2019

Accepted July 17, 2019

Published online September 12, 2019
1.20 (0.51-2.83)), 68.4\% vs $75.0 \%$ for DBP (AOR 0.70 (0.24-2.09)), and $35.5 \%$ vs $33.8 \%$ for both (AOR 1.03 (0.44-2.42)). Change in absolute SBP and DBP did not differ significantly between the groups at 6 or 12 months. Exploratory post hoc analysis revealed intervention benefit only occurred among individuals whose providers intensified their regimens, but not among those with intensification but no intervention.

CONCLUSIONS: The intervention achieved short-term improvement in SBP control in a highly disadvantaged population. Despite attempts to enhance intrinsic motivation, the effect was not sustained after incentives were withdrawn. Future research should evaluate combined patient/provider strategies to enhance such interventions and sustain their benefit.

TRIAL REGISTRATION: NCT0 1402453; http: / / clinicaltrials.gov/show/NCT01402453

KEY WORDS: hypertension; healthcare disparities; patient behavior; financial incentives, behavioral economics.

J Gen Intern Med 35(1):70=8

DOI: $10.1007 / \mathrm{s} 11606-019-05269-Z$

(C) Society of General Internal Medicine 2019

\section{INTRODUCTION}

Uncontrolled hypertension remains a substantial societal challenge. Its asymptomatic nature and delay in adverse complications reduce risk perception while medication cost and fear of side-effects deter treatment-seeking behavior. ${ }^{1}$ Interventions to improve hypertension control have emphasized screening, ${ }^{2-6}$ patient awareness of hypertension's consequences, ${ }^{7}$ adjusting dosing schedules and packaging, other measures to improve adherence, ${ }^{8-14}$ physician awareness of need to treat, ${ }^{15,16}$ and physician incentives to overcome therapeutic inertia and achieve recommended blood pressure (BP) treatment targets. ${ }^{17}$ The most successful interventions have been pharmacist team-based programs in large integrated health systems. ${ }^{18-20}$ While hypertension control in the USA 
has improved, BP remains $\geq 140 / 90 \mathrm{mmHg}$ (the standard definition of uncontrolled hypertension) among half of affected individuals. ${ }^{21}$ This challenge is especially pronounced among racial/ethnic minority populations, who are at greater risk for uncontrolled hypertension and its complications, and among socioeconomically disadvantaged persons facing many competing demands and limited resources. ${ }^{22}$

Financial incentives are a potentially promising approach to improving hypertension control. Provider incentives have been adopted widely in quality improvement efforts. ${ }^{23}$ In theory, financial incentives might help patients focus attention on treatment initially, but they may not have enduring impact on chronic conditions requiring long-term treatment if they cannot be continued for extensive periods. ${ }^{24}$

We hypothesized that monetary payments, designed using behavioral economics principles, would strongly incentivize behavior change and hypertension control among economically disadvantaged individuals, particularly if combined with an additional intervention element designed to prompt attribution of behavior changes to internal motivation - in this case, personal values, priorities, goals, and needs ${ }^{25,26}$ that might also increase the chances of sustaining the effect after the intervention ended.

To test this hypothesis, we conducted a randomized trial of a patient-centered intervention, combining financial incentives with intrinsic motivation tools, to improve hypertension control among adults attending Federally Qualified Health Center clinics (FQHCs). For both the intervention and comparison groups, we provided educational materials, home BP monitors (and training in their use), and monthly clinic BP checks. Intervention participants also received contingent payments and an "identity intervention" designed to increase intrinsic motivation to achieve and sustain hypertension control.

\section{METHODS}

Design and Setting. The two-arm randomized controlled trial was conducted in three Los Angeles area FQHC sites serving indigent patients without insurance or with publicly provided insurance who were overwhelmingly Latino and African American.

Participants. The target population, clinic patients aged $\geq$ 18 years with uncontrolled hypertension, were recruited by waiting room signage and clinic staff. We screened for systolic $\mathrm{BP}(\mathrm{SBP}) \geq 149 \mathrm{mmHg}(10 \mathrm{mmHg}$ above the target level) and/ or diastolic BP (DBP) $\geq 94 \mathrm{mmHg}(5 \mathrm{mmHg}$ above the target level) in two steps. After patients rested $5 \mathrm{~min}$ in a quiet room, trained research personnel measured seated BP from the dominant arm (at heart level) with an appropriately sized cuff using a validated automated oscillometric sphygmomanometer (Welch Allyn, Series 52,000, Arden, NC) to eliminate digit preference and minimize inter-observer variability. We discarded the first two of six readings, averaging the final four. ${ }^{27,}{ }^{28}$ Participants averaging $\mathrm{SBP} \geq 149 \mathrm{mmHg}$ and/or DBP $\geq 94 \mathrm{mmHg}$ were invited to return within 1 week for a second screening. We invited those remaining abnormal to provide written informed consent in Spanish or English for trial participation.

Study Procedures. We randomly allocated consenting participants 1:1 to intervention and comparison groups. Research staff did not interact with participants' clinicians regarding BP control after randomization nor inform them of condition assignment. Both groups were administered in-person questionnaires at baseline and 6 and 12 months. Structured response items included demographic characteristics, clinical history including history of hypertension and hypertension treatment, current medications, health status (measured with the SF12 ), ${ }^{29}$ self-efficacy (a 5-item version of the Medication Adherence Self-Efficacy Scale (MASES) adapted for use in hypertension, ${ }^{30,}{ }^{31}$ Patient Activation Measure score (the PAM-6), ${ }^{32} 6$ items measuring social support (drawn from Medical Outcomes Study and the Lubben Social Network Scale-6), ${ }^{33}, 34$ access to care (6 items), and unmet needs ( 2 items derived from the HCSUS study). ${ }^{35}$ Intervention participants only were administered items to identify potential reasons to stay healthy or live longer (e.g., relationships, responsibilities to others, life goals and activities they enjoy) and were asked to provide pictures of loved ones, favored activities or representations of goals that we incorporated into personalized calendars for the identity (intrinsic motivation) manipulation. We asked members of both groups to return monthly for 6 months, and at months 9 and 12 for BP checks. Enrollment began in October 2011; follow-up was completed in January 2014. We provided both groups with digital home BP monitors (Lifesource or Meridian) that recorded measurements and dates, training by study staff in their use, and encouragement to use them, but only intervention participants received financial incentives for doing so (if they brought the monitor to the visit).

Payments to Participants. We offered intervention participants a combination of fixed payments, contingent payments, and lotteries: \$10 per visit at months 1-6 for returning, and additional payments if they brought in their personalized calendar (\$5) and BP monitor (\$5). At each visit through 6 months, we also provided contingent payments of $\$ 2$ per mm of SBP and DBP improvement from their values at study entry, up to achieving target clinic BP values $(\mathrm{SBP}<$ $140 \mathrm{mmHg}$ or $\mathrm{DBP}<90 \mathrm{mmHg}$ ) to a maximum of $\$ 50$ per visit; if visit $\mathrm{BP}$ was in the target range, minimum payment was $\$ 30$. The target level of $<140 / 90$ was consistent with JNC 7's Guideline goal for office BP, operative during the study period. ${ }^{36}$ To avoid inducing inappropriate measures to lower BP, no payment was given for improvement beyond BP 139/ $89 \mathrm{mmHg}$ or for total (SBP plus DBP) improvement of > $25 \mathrm{mmHg}$ from baseline values. Finally, because people tend 
to value lotteries offering low probability of reward more than the reward's expected value ${ }^{37}$, making them cost-effective extrinsic motivators for complying with health-related behaviors, ${ }^{24}$ intervention participants also received one chance to draw a lottery card during each intervention visit (months one through 6) for each of 3 desired health behaviors: (1) recording hypertension medication use on the calendar on $\geq 50 \%$ of days in the preceding month, (2) measuring their $\mathrm{BP}$ on $\geq 50 \%$ of days in the month, and (3) achieving BP goals or improved BP relative to the previous visit. Lottery cards had values of $\$ 0$ (83\%), \$20 (10\%), \$50 (5\%), or \$100 (2\%). Winnings were combined with payments for BP improvement and other incentives and were provided in gift cards (additional detail in the online Appendix).

Comparison group participants received $\$ 20$ at each study visit months 1 through 6 to assure adequate and comparable follow-up, but no contingent or lottery payments. Both groups received additional payments for completing study questionnaires and \$20 per visit for returning for BP checks at 9 and 12 months (after the 6-month intervention had ended).

Identity Intervention. The identity intervention was designed to promote internalization of motivation for controlling hypertension by associating healthy behaviors with personal values and needs. ${ }^{25} \mathrm{We}$ provided participants with personalized calendars, containing images of loved ones, activities or life goals associated with being healthy that they identified, to use daily for recording medication use. A research associate met with intervention participants at months 1 through 6 , prompting participants to talk about what improved BP would mean for loved ones, goals, activities, and responsibilities. When participants received lottery tickets and/or contingent payments for effort (measuring BP, taking medicine, bringing in calendars, and BP monitors) or results (improved BP), the research associate prompted them to relate that to reasons they identified for staying healthy or living longer (e.g., "so that you can dance at your daughter's wedding," or “....care for loved ones.”). ${ }^{26}$

Data on Hypertension Treatment. We abstracted clinic records and collected self-report information about hypertension medications and regimen changes or intensification from 167 of 173 participants (97\%) completing 6 months follow-up and from 153 of $158(97 \%)$ at 12 months, in addition to baseline self-reports.

Statistical Analysis. The study's co-primary outcomes were intervention efficacy on SBP control rate and on DBP control rate (measured as group differences in the percentage achieving in-clinic BP target values after 6 months (SBP < $140 \mathrm{mmHg}$, DBP < $90 \mathrm{mmHg}$ )), and absolute SBP and DBP reduction (although the intervention was structured only to lower BP to the point of hypertension control (139/89) and not to reward $>25 \mathrm{~mm}$ of total SBP plus DBP reduction). The study's priority secondary outcome was sustainability of the intended intervention effect. This was measured by group differences in SBP and DBP control rates at 12 months ( 6 months after the intervention ended). We used mixed effects logistic regression models to assess these key outcomes and linear mixed effects models, with baseline BP as a key covariate, to test for intervention effects on SBP and DBP at 6 and 12 months. We assessed differences in patient-reported outcomes, using analysis of covariance (ANCOVA) models adjusting for baseline values. Our target sample size of 262, assuming standard deviations of $20 \% / 15 \%$ for SBP/DBP and a completion rate of $75 \%$, would have provided .80 power at the .05 significance level (two-sided test) to detect control rate differences of $60 \%$ vs $40 \%$ and .87 power to detect differences of $40 \%$ vs $20 \%$. Our final sample (limited by clinic patient availability and study resources) was 207 ; the completion rate was $87.0 \%$ of the original target at 6 months and $80.4 \%$ at 12 months, for power respectively of .75 to .82 and .71 to .78 (online Appendix Table 1). We also conducted exploratory post hoc subgroup analyses of potential effects of nonrandom drug regimen intensification on group differences in BP and related outcomes. Intensification was defined as an increased dose of an existing hypertension medication, adding a new medication, or substituting a more potent medication. $P$ values of $<0.05$ were considered statistically significant. All analyses were performed using SAS v. 9.3 (SAS Institute Inc., Cary, $\mathrm{NC})$.

The UCLA Institutional Review Board approved the research protocol.

\section{RESULTS}

Cohort recruitment and retention are shown in Figure 1. Among 999 clinic patients initially screened, 531 did not meet the BP screening criteria or did not return for the second screening. Of 468 completing the second screening, 220 met BP eligibility criteria, of whom 207 consented and were enrolled: 103 randomly allocated to the intervention group and 104 to the comparison group. Eleven participants were lost to follow-up immediately after enrollment, and 38 others over the next 12 months. Thus, follow-up was $82.6 \%$ at 6 months and $76.3 \%$ at 12 months. Attrition did not differ significantly between study groups $(P>0.80)$. Of 49 participants not completing the study, 11 moved away from Southern California and two expired (one in each study arm). Excluding those lost immediately after enrollment, subjects attended $84.2 \%$ of intervention visits and $86.3 \%$ of control visits during the 6-month intervention. Participant payments at visits in months 1 to 6 averaged $\$ 74.43$ (including $\$ 20.85$ for lotteries and $\$ 31.32$ for BP improvement) for intervention attendees and \$23.33 for control attendees. Total study payments averaged $\$ 424.72$ among intervention participants, including those lost to follow-up (range $\$ 40$ to $\$ 846$ ) (online Appendix). 


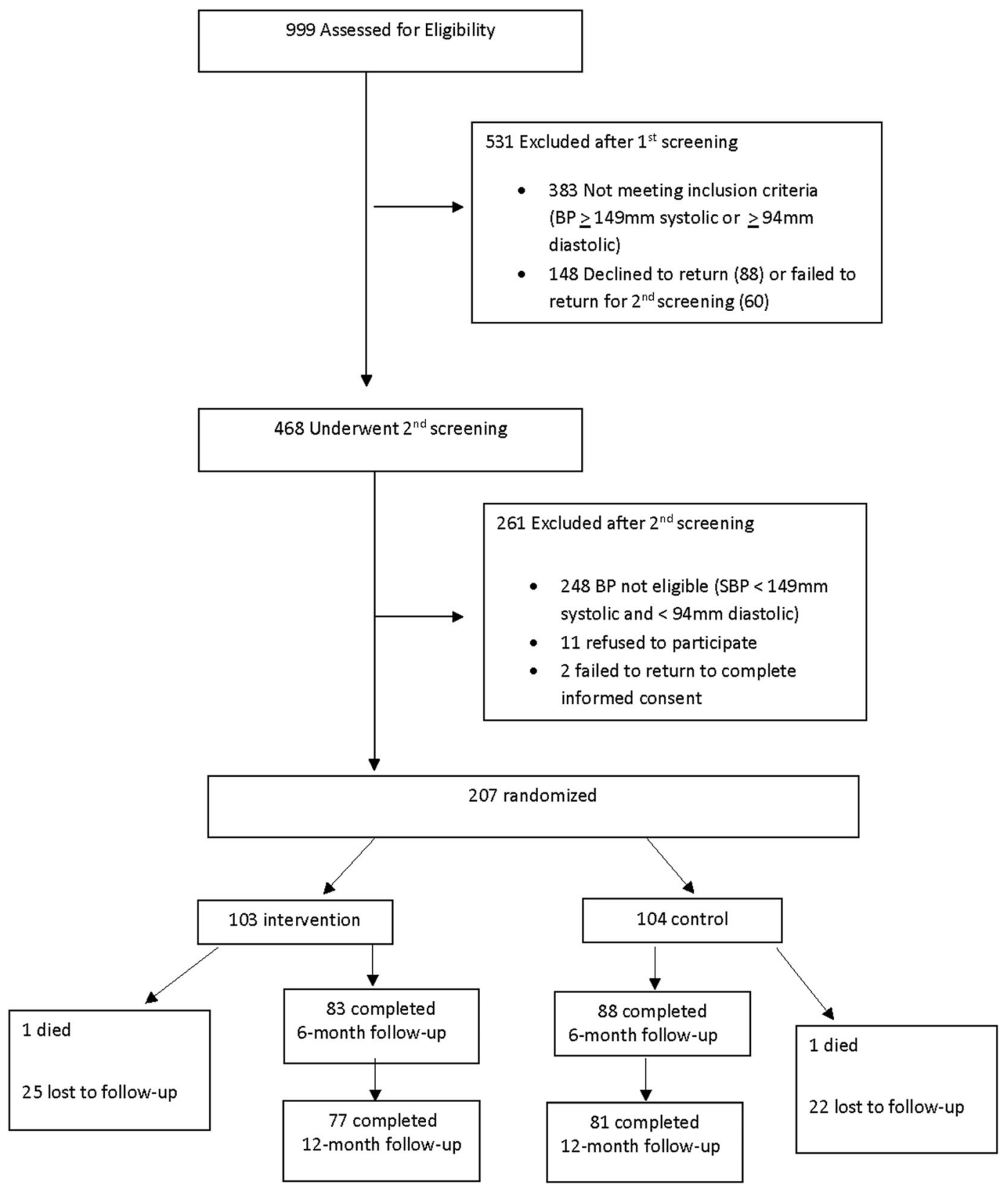

Figure 1 Consort flow diagram.

The groups were well-matched on most baseline characteristics (Table 1), including rates of prior hypertension diagnosis $(P=0.21)$, prior hypertension treatment $(P=0.84)$, and current numbers of hypertension medicines $(P=0.39)$. Overwhelmingly Black or Latino, and having very low household incomes, most were immigrants and 2 in 5 were diabetics. Participants reported severe resource constraints: $41.2 \%$ had gone without health care when needing money for food, clothing or housing; $21.9 \%$ had forgone food, clothing or housing to pay for health care.

Subjects entered the trial with marked systolic hypertension and less marked diastolic hypertension, representing stage 2 hypertension (significantly elevated BP requiring medication therapy plus lifestyle modification) by both JNC 7 and 2017 ACC/AHA guideline criteria. ${ }^{36,38}$ Mean baseline BP was
$162.3( \pm 14.5) / 91.6( \pm 14.2) \mathrm{mmHg}$ among intervention group participants and $161.8( \pm 14.1) / 88.7( \pm 12.8) \mathrm{mmHg}$ among comparison group participants.

Logistic regression revealed that intervention participants were significantly more likely to achieve $\mathrm{SBP}<140 \mathrm{mmHg}$.at 6 months $(57.1 \%$, vs. $40.2 \%,(P=0.02)$, controlling for age, gender, education, race/ethnicity, born in the USA, and diabetes (Table 2). At 12 months (6 months after the intervention ended), 39.5\% of intervention participants and $35.0 \%$ of comparison participants had normal range SBP $(P=0.68)$ (Table 2). DBP fell by lesser amounts: nearly half were normal at baseline and over $70 \%$ at 6 and 12 months. There were nonsignificant trends toward greater control in intervention participants at 6 months of DBP $(79.8 \%$, vs. $70.1 \%, P=$ 
Table 1 Baseline Characteristics of Study Population

\begin{tabular}{|c|c|c|}
\hline & \multirow{2}{*}{$\begin{array}{l}\begin{array}{l}\text { Enhanced } \\
\text { intervention }\end{array} \\
N=103\end{array}$} & \multirow{2}{*}{$\begin{array}{l}\overline{\text { Comparison }} \\
N=104\end{array}$} \\
\hline & & \\
\hline Male, $n(\%)$ & $56(54.4)$ & $50(48.1)$ \\
\hline Age (years), mean (SD) & $52.8(10.3)$ & $54.6(12.3)$ \\
\hline \multicolumn{3}{|l|}{ Race/ethnicity, $n(\%)$} \\
\hline Hispanic/Latino & $64(64.6)$ & $65(65.0)$ \\
\hline Non-Hispanic Black & $33(33.3)$ & $33(33.0)$ \\
\hline Other & $2(2.0)$ & $2(2.0)$ \\
\hline Born in the USA, $n(\%)$ & $41(40.6)$ & $43(41.7)$ \\
\hline \multicolumn{3}{|l|}{ Marital status, $n(\%)$} \\
\hline Never married & $35(35.4)$ & $35(35.0)$ \\
\hline Married & $35(35.4)$ & $31(31.0)$ \\
\hline Formerly married & $29(29.3)$ & $34(34.0)$ \\
\hline \multicolumn{3}{|l|}{ Education, $n(\%)$} \\
\hline$<12$ years & $59(59.0)$ & $60(58.3)$ \\
\hline 12 years & $23(23.0)$ & $25(24.3)$ \\
\hline$>12$ years & $18(18.0)$ & $18(17.5)$ \\
\hline Income $<\$ 10,000, n(\%)$ & $70(76.1)$ & $65(74.7)$ \\
\hline \multicolumn{3}{|l|}{ Employment, $n(\%)$} \\
\hline Employed for pay & $23(23.7)$ & $18(18.2)$ \\
\hline Looking for work & $25(25.8)$ & $26(26.3)$ \\
\hline Other & $49(50.6)$ & $55(55.5)$ \\
\hline \multicolumn{3}{|l|}{ Self-reported history, $n(\%)$} \\
\hline Diabetes & $39(39.8)$ & $42(41.6)$ \\
\hline Heart failure & $8(8.2)$ & $12(12.0)$ \\
\hline High cholesterol & $46(47.9)$ & $47(46.5)$ \\
\hline Heart attack & $9(9.2)$ & $9(8.8)$ \\
\hline Stroke & $7(7.1)$ & $10(9.8)$ \\
\hline Asthma & $7(7.1)$ & $16(15.7)$ \\
\hline Chronic kidney disease & $2(2.1)$ & $11(11.1)$ \\
\hline None of the above & $36(36.7)$ & $25(24.8)$ \\
\hline \multicolumn{3}{|l|}{ Hypertension history } \\
\hline Prior diagnosis, $n(\%)$ & $91(91.9)$ & $97(97.0)$ \\
\hline Prior treatment, $n(\%)$ & $91(91.9)$ & $91(90.1)$ \\
\hline Currently using BP & $92(92.9)$ & $88(88.0)$ \\
\hline \multicolumn{3}{|l|}{ medications, $n(\%)$} \\
\hline Current number of BP & $1.85(1.14)$ & $1.72(1.08)$ \\
\hline $\begin{array}{l}\text { Current taking > }>3 \mathrm{BP} \\
\text { medications, } n(\%)\end{array}$ & $6(6.0)$ & $5(5.0)$ \\
\hline $\begin{array}{l}\text { medications, } n(\%) \\
\text { SF12 aggregate physical health } \\
\text { scoret, mean (SD) }\end{array}$ & $40.0(11.3)$ & $37.9(10.4)$ \\
\hline $\begin{array}{l}\text { SF12 aggregate mental health } \\
\text { scoret mean (SD) }\end{array}$ & $46.1(12.6)$ & 43.7 (11.7) \\
\hline Self-efficacy score $†$, mean (SD) & $8.1(1.9)$ & $7.8(1.9)$ \\
\hline $\begin{array}{l}\text { Patient activation measure } \\
\text { score } \dagger, \text { mean (SD) }\end{array}$ & $72.3(20.4)$ & $70.1(22.1)$ \\
\hline
\end{tabular}

There were no significant differences in baseline characteristics, except for self-reported history of chronic kidney disease $(P<0.05)$

†Range of possible scores: patient activation measure 0-100, selfefficacy 1-10, SF-12 physical and mental health 0-100. Higher is better for all scores

$0.10)$, and of both SBP and DBP (53.6\% vs. $40.2 \%, P=0.08)$, but not at 12 months for either of these outcomes (Table 2). Mean BP fell to $141.9( \pm 16.6) / 81.1( \pm 13.9) \mathrm{mmHg}$ in intervention participants vs. $146.1( \pm 18.9) / 80.4( \pm 15.0) \mathrm{mmHg}$ in the comparison group at 6 months $(P=0.18$ by linear regression of SBP difference in differences, controlling for these same variables). Differences in reduction of SBP at 12 months and DBP at 6 and 12 months were not significant (Table 3). Both intention-to-treat and completer analyses, with and without the same adjustments, yielded similar results (data not reported).

Intervention participants significantly improved relative to comparison participants in physical health (SF-12) $(P=0.008)$ at 6 months, and in self-efficacy scores at 12 months $(P=0.03)$
(Table 4). Intervention subjects' BP monitors recorded BP measurements on $\geq 15$ days in the month before $77.6 \%$ of all visits in months 1 to 6 .

The exploratory post hoc analysis found that improved SBP control in intervention relative to comparison participants was highly significant in the subset of subjects whose regimens were intensified (67\% among intervention participants vs. $35 \%$ among comparison participants, $P=0.02$ ), but not among those whose regimens were not intensified $(53 \%$ vs $46 \%$ respectively, $P=0.51$ ). At 6 months, mean SBP fell by $29 \mathrm{mmHg}$ in intensified intervention participants vs $18 \mathrm{mmHg}$ in intensified comparison participants $(P=0.02)$; among those not intensified, SBP fell $15 \mathrm{mmHg}$ and $16 \mathrm{mmHg}$, respectively $(P=0.89)$. Also, the intervention effect on self-efficacy scores was limited to participants in whom drug regimens had been intensified (online Appendix Table 2). No analyses revealed significant benefit of intensification overall (without respect to experimental group assignment).

\section{DISCUSSION}

To address the challenging problem of hypertension control among disadvantaged populations, ${ }^{39}$ we completed a randomized trial of a novel behavior theory-based intervention combining monetary incentives with intrinsic motivation tools to promote specific patient behaviors (self-measurement of BP, medication adherence, and clinic visits) and $\mathrm{BP}$ reduction, to achieve and sustain recommended BP targets. In our severely disadvantaged cohort of Latino and African American safetynet clinic patients, we found a significant intervention effect on SBP control after 6 months, with trends in control of DBP and of both SBP and DBP that fell short of being statistically significant: a clinic SBP of $<140 \mathrm{mmHg}$ was achieved by $17 \%$ more of intervention participants than comparison participants. The intervention effect did not persist after both components of the intervention were withdrawn. This finding compares favorably with a recent study of Medicaid patients with hypertension, in which financial incentives alone did not affect BP control, although most patients in that study were normotensive at study entry. ${ }^{40}$

At first glance, the intervention effect seems modest: absolute SBP improved only about a nonsignificant $4 \mathrm{mmHg}$ more in intervention than comparison participants, but we note that the intervention was designed to reach the target level of hypertension control and did not reward improvement beyond that level. The $57 \%$ of intervention group patients achieved SBP control is less than the $>80 \%$ achieved in KaiserPermanente's population (with providers implementing a system-wide BP medication intensification protocol ${ }^{20}$ ), but our manipulation was strictly patient-centered, with no intervention on care intensity, quality, or structure. This said, in our population, the SBP control achieved by the intervention is an important accomplishment for several reasons. Typical of FQHCs, participants were largely unemployed, impoverished, 
Table 2 Mixed Effects Logistic Regression Model for Blood Pressure Control at 6 and 12 Months

\begin{tabular}{|c|c|c|c|c|c|}
\hline & \multicolumn{2}{|c|}{$\%$ Controlled $^{*}$} & \multirow[t]{2}{*}{ Adjusted odds ratio } & \multirow[t]{2}{*}{$95 \%$ confidence interval } & \multirow[t]{2}{*}{$P$ value } \\
\hline & Intervention & Comparison & & & \\
\hline \multicolumn{6}{|l|}{ Systolic BP } \\
\hline 0 month & 0 & 1.9 & & & \\
\hline 6 months & 57.1 & 40.2 & 2.53 & $1.13-5.70$ & 0.02 \\
\hline 12 months & 39.5 & 35 & 1.20 & $0.51-2.83$ & 0.68 \\
\hline \multicolumn{6}{|l|}{ Diastolic BP } \\
\hline 0 month & 46.6 & 48.1 & & & \\
\hline 6 months & 79.8 & 70.1 & 2.50 & $0.84-7.44$ & 0.10 \\
\hline 12 months & 68.4 & 75 & 0.70 & $0.24-2.09$ & 0.52 \\
\hline \multicolumn{6}{|c|}{ Both systolic and diastolic BP } \\
\hline 0 months & 0 & 0 & & & \\
\hline 6 months & 53.6 & 40.2 & 2.04 & $0.92-4.52$ & 0.08 \\
\hline 12 months & 35.5 & 33.8 & 1.03 & $0.44-2.42$ & 0.94 \\
\hline
\end{tabular}

Mixed effects logistic regression model controlling for age at enrollment, gender, education, racelethnicity, born in the USA, and diabetes. Subjects attending study follow-up visits at months 1-6, 9, 12: intervention group $(N=103): 83,78,84,79,77,83,71,77 ; 7$ subjects dropped out prior to any follow-up visit; control group $(N=104)$ : $95,90,82,87,85,88,77,81 ; 4$ dropped out prior to any follow-up visit. Follow-up rates for intervention and control subjects were $80.6 \%$ and $84.6 \%$ at 6 months and $74.8 \%$ and $77.9 \%$ at 12 months. Additional details in the Appendix

$\neq$ Results presented are excluding participants lost to follow-up. Results were similar including those individuals

and had low educational attainment. Many were recent immigrants. They had high rates of serious comorbid conditions that compete with hypertension for theirs and their providers' attention, and severely constrained resources for allocation to health care, which also may inhibit cognitive resources to cope with disease. ${ }^{41}$ Such populations are poorly represented in most hypertension trials. In such high-risk individuals, even modest BP improvements can substantially reduce risk of complications and death.

The positive intervention effect occurred despite substantial BP improvement in comparison participants, a common finding in hypertension trials, due to regression to the mean ${ }^{42}$ and the Hawthorne effect of study participation. ${ }^{43}$ Moreover, in this trial, the control condition was an active comparator, receiving financial incentives (to assure adequate follow-up) for frequent BP checks, and training and equipment for BP self-measurement, which enhances medication adherence. ${ }^{44}$ These interventions likely constituted a significant behavioral intervention.

Monetary payment can induce short-term (and sometimes longer-term) health behavior changes, such as smoking cessation and healthy eating ${ }^{45,}{ }^{46}$ but impact on medical conditions requiring long-term medication use is mixed $^{47-52}$ For example, use of lotteries increased short-term warfarin adherence, but the effect disappeared after the incentive was removed. ${ }^{24}$ Sustained benefit in chronic disease care may require continued payments (particularly in populations with many competing demands and challenges), or additional interventions to promote patient attribution of behavior change to internal motivation, ${ }^{26}$ or to influence clinician behavior. ${ }^{50}$ Our incentive payments were substantial relative to participants' very low incomes (averaging $>4 \%$ of annual income). This may have enhanced their salience. An undermining or "crowding out" effect of external rewards on intrinsic motivation, identified in some social psychology and economics studies, ${ }^{53,54}$ is heterogeneous and has not been reported in medical care studies that have looked for such effects ${ }^{52,55-57}$ In our study, the initial effect on SBP control was not sustained after the intervention ended, even though we combined the external motivator (contingent and lottery payments) with an internal one. Improvement at 12 months in self-efficacy for BP medication adherence could suggest more enduring effects of the intervention on attitudes to controlling their BP, even if they did not translate into sustained improved BP control, but that finding should be interpreted cautiously, since selfefficacy did not differ at 6 months, and intrinsic motivation was not measured directly.

Besides achieving short-term SBP improvement in highrisk, highly disadvantaged minority patients by deploying a theory-based behavioral intervention along with financial incentives, the study's strengths include high cohort retention and rigorous assessment of $\mathrm{BP}$ outcomes.

Table 3 Mixed Effects Linear Regression Model for Blood Pressure Change

\begin{tabular}{|c|c|c|c|c|c|}
\hline & Intervention group & Comparison group & Estimate of difference & SE & $P$ value \\
\hline \multicolumn{6}{|c|}{ Systolic BP mmHg (SD) } \\
\hline Baseline & $162.3(14.5)$ & $161.8(14.1)$ & & & \\
\hline 6 months & $141.9(16.6)$ & $146.1(18.9)$ & -3.73 & 2.79 & 0.18 \\
\hline 12 months & $147.5(17.8)$ & $149.9(21.1)$ & -1.17 & 2.90 & 0.69 \\
\hline \multicolumn{6}{|c|}{ Diastolic BP mm Hg (SD) } \\
\hline Baseline & $91.6(14.2)$ & $88.7(12.8)$ & & & \\
\hline 6 months & 81.1 (13.9) & $80.4(15.0)$ & -1.19 & 1.65 & 0.47 \\
\hline 12 months & $84.6(10.9)$ & $81.7(14.6)$ & 1.66 & 1.71 & 0.33 \\
\hline
\end{tabular}

Controlling for baseline blood pressure, age, gender, racelethnicity, education, born in the USA, and diabetes, and excluding persons lost to follow-up. Models including such subjects produced similar results 
Table 4 Patient-Reported Outcomes

\begin{tabular}{|c|c|c|c|}
\hline & $\begin{array}{l}\text { Intervention } \\
\text { mean (S.D.) }\end{array}$ & $\begin{array}{l}\text { Comparison } \\
\text { mean (S.D.) }\end{array}$ & $\begin{array}{l}P \text { value of } \\
\text { difference }\end{array}$ \\
\hline \multicolumn{4}{|c|}{ Patient activation measure score } \\
\hline 6 months & $0.9(19.7)$ & $3.2(28.1)$ & 0.83 \\
\hline 12 months & $3.7(18.6)$ & $5.5(26.1)$ & 0.45 \\
\hline \multicolumn{4}{|c|}{ Self-efficacy score } \\
\hline 6 months & $0.1(2.2)$ & $0.0(2.1)$ & 0.50 \\
\hline 12 months & $0.7(2.1)$ & $0.3(1.9)$ & 0.03 \\
\hline \multicolumn{4}{|c|}{ SF12 aggregate physical health score } \\
\hline 6 months & $2.0(9.8)$ & $-1.0(9.5)$ & 0.008 \\
\hline \multicolumn{4}{|c|}{ SF12 aggregate mental health score } \\
\hline 6 months & $1.4(11.7)$ & $1.7(10.4)$ & 0.49 \\
\hline
\end{tabular}

ANCOVA higher is better for all scores, which are presented as change from the baseline values reported in Table 1.

Our study also has important limitations. We bundled two interventions to maximize chances of demonstrating an effect. Differentiating their effects would require more than two study arms, exceeding our budgetary constraints. An effective, combined intervention may prove clinically useful in very challenging populations, even though additional studies would be needed to assess whether fewer intervention elements would suffice. The study was powered to detect, at the $P=0.05$ confidence level, differences in BP normalization rates of about $20 \%$. Powering the study to detect smaller differences potentially beneficial to health would require a larger sample size per study arm than our budget allowed. We note further that participants and study personnel could not be blinded to condition assignment, though assignment information was not shared with participants' medical providers and clinic staff. Without engaging providers and clinic staff in the intervention or in implementing a clinic-wide team-based BP medication intensification protocol (as in the recent SBP Intervention Trial $^{58}$ ), the effect on hypertension control was modest and not sustained after the intervention ended.

The post hoc analysis findings on medication intensification must be interpreted cautiously; it was not planned a priori, and intensification was not randomized. The associations observed suggest that patient interventions to improve and sustain BP control may require additional measures to assure that providers respond to uncontrolled BP with guideline-directed regimen adjustments.

Despite these limitations, we found that behaviorally informed incentives plus an intervention designed to increase intrinsic motivation to sustain good health increased the likelihood of achieving SBP normalization in a disadvantaged minority population. Additional refinements are needed to develop a more potent and sustainable patient-centered intervention that coordinates intrinsic and extrinsic patient motivators with improvement in quality and intensity of medical care.

Future studies should investigate the impact of intensifying and/or extending the identity intervention, extending the period of provision of financial incentives, or both, and whether interventions targeting behavior of both patients and providers are more effective than those directed at either one alone. For example, a study could assess coupling a patientcentered behavioral intervention in highly disadvantaged patients with a system intervention to overcome physician inertia in intensifying BP regimens, as was accomplished using pharmacists in a recent trial among black male barber shop clients. ${ }^{59}$ While patient and provider interventions in hypertension care are somewhat costly, these costs are likely to be dwarfed by reduction of downstream costs of treating hypertensive complications - non-fatal stroke, myocardial infarction, heart failure, end-stage kidney disease - and the social and economic costs of higher morbidity.

Acknowledgments: Dr. Ronald G. Victor made numerous invaluable contributions to the design of the study, interpretation of the results, and development and critical review of the manuscript prior to his death on September 10, 2018.

Corresponding Author: Martin F. Shapiro, MD, CM, PhD; Division of General Internal Medicine Weill Cornell Medical College, 420 East 70th Street, LH340, New York, NY 10021 , USA (e-mail: mfs2004@med.cornell.edu).

Funding Sources This project was funded by the NIH (RC4AG039077 from the National Institute on Aging and UL1-TROO1881 from the National Center for Advancing Translational Sciences). The sponsors had no role in the design and conduct of the study, nor in the collection, management, analysis, or interpretation of the data, nor in the preparation, review, or approval of the manuscript, nor in the decision to submit the manuscript for publication.

\section{Compliance with Ethical Standards:}

Conflict of Interest: The authors declare that they do not have a conflict of interest.

\section{REFERENCES}

1. Victor RG, Leonard D, Hess P, et al. Factors Associaed with Hypertension Awareness, Treatment, and Control in Dallas County, Texas, Arch Intern Med. 2008;168(12):1285-93.

2. Wilber JA, Barrow JG. Hypertension-a community problem. Am J Med. 1972;52(5):653-63.

3. Stamler J, Stamler R, Riedlinger WF, Algera G, Roberts RH. Hypertension screening of 1 million Americans. Community Hypertension Evaluation Clinic (CHEC) program, 1973 through 1975. JAMA. 1976;235(21):2299-306.

4. Blood pressure studies in 14 communities. A two-stage screen for hypertension. JAMA. 1977;237(22):2385-91.

5. Radice M, Alberti D, Alli C, Avanzini F, Di Tullio M, Mariotti G, et al. Long-term efficacy of screening for hypertension in a community. J Hypertens. 1985;3(3):255-9.

6. Cooke CJ, Meyers A. The Role of Community Volunteers in Health Interventions: a Hypertension Screening and Follow-Up Program. Am J Public Health. 1983;73(2): 193-4.

7. Ambrosio GB, Strasser T, Dowd JE, Tuomilehto $J$, Nissinen A, Froment A, et al. Effects of Interventions on Community Awareness and Treatment of Hypertension: Results of a WHO Study. Bull World Health Organ. 1988;66(1):107-13.

8. Baird MG, Bentley-Taylor MM, Carruthers SG, Dawson KG, Laplante LE, Larochelle P, et al. A Study of Efficacy, Tolerance and Compliance of Once-Daily Versus Twice-Daily Metoprolol (Betaloc) in Hypertension. Betaloc Compliance Canadian Cooperative Study Group. Clin Invest Med. 1984;7(2):95-102. 
9. Becker LA, Glanz K, Sobel E, Mossey J, Zinn SL, Knott KA. A Randomized Trial of Special Packaging of Antihypertensive Medications. J Fam Pract. 1986;22(4):357-61.

10. Brown BG, Bardsley J, Poulin D, Hillger LA, Dowdy A, Maher VM et al. Moderate Dose, Three-Drug Therapy with Niacin, lovastatin, and Colestipol to Reduce Low-Density Lipoprotein Cholesterol $<100 \mathrm{mg} / \mathrm{dl}$ in Patients with Hyperlipidemia and Coronary Artery Disease. Am J Cardiol. 1997;80(2):111-5.

11. Friedman RH, Kazis LE, Jette A, Smith MB, Stollerman J, Torgerson $\mathbf{J}$, et al. A Telecommunications System for Monitoring and Counseling Patients with Hypertension. Impact on Medication Adherence and Blood Pressure Control. Am J Hypertens. 1996;9(4 Pt 1):285-92.

12. Girvin B, McDermott BJ, Johnston GD. A Comparison of Enalapril 20 mg Once Daily versus 10 mg Twice Daily in Terms of Blood Pressure Lowering and Patient Compliance. J Hypertens. 1999;17(11):1627-31.

13. Haynes RB, Sackett DL, Gibson ES, Taylor DW, Hackett BC, Roberts RS, et al. Improvement of Medication Compliance in Uncontrolled Hypertension. Lancet. 1976;1(7972):1265-8.

14. Johnson AL, Taylor DW, Sackett DL, Dunnett CW, Shimizu AG. Selfrecording of Blood Pressure in the Management of Hypertension. Can Med Assoc J. 1978;119(9):1034-9.

15. Mosca L, Linfante AH, Benjamin EJ, Berra K, Hayes SN, Walsh BW, et al. National Study of Physician Awareness and Adherence to Cardiovascular Disease Prevention Guidelines. Circulation. 2005;111(4):499510 .

16. Hagemeister J, Schneider CA, Barabas S, Schadt R, Wassmer G Mager G, et al. Hypertension Guidelines and Their Limitations-the Impact of Physicians' Compliance as Evaluated by Guideline Awareness. J Hypertens. 2001;19(11):2079-86

17. Millett C, Gray J, Bottle A, Majeed A. Ethnic Disparities in Blood Pressure Management in Patients with Hypertension after the Introduction of Pay for Performance. Ann Fam Med. 2008;6(6):490-6.

18. Tsuyuki RT, Houle SKD, Charrois TL, Kolber MR, Rosenthal MM, Lewanczuk R, et al. A Randomized Trial of the Effect of Pharmacis Prescribing on Improving Blood Pressure in the Community: The Alberta Clinical Trial in Optimizing Hypertension (RxACTION). Circulation. 2015;132(2):93-100.

19. Victor RG. Expanding Pharmacists' Role in the Era of Health Care Reform. Am J Health Syst Pharm. 2012;69(22):1959.

20. Jaffe MG, Lee GA, Young JD, Sidney S, Go AS. Improved Blood Pressure Control Associated with a Large-Scale Hypertension Program. JAMA. 2013;310(7):699-705.

21. Poulter NR, Prabhakaran D, Caulfield M. Hypertension. Lancet. 2015;386(9995):801-12.

22. Mullainthan S, Shafir E. Scarcity: Why Having so Little Means so Much New York, Times Books, Henry Holt and Company, 2013.

23. Houle SK, McAlister FA, Jackevicius CA, Chuck AW, Tsuyuki RT. Does Performance-Based Remuneration for Individual Health Care Practitioners Affect Patient Care?: A Systematic Review. Ann Intern Med 2012;157(12):889-99.

24. Volpp KG, Loewenstein G, Troxel AB, Doshi J, Price M, Laskin M, et al. A Test of Financial Incentives to Improve Warfarin Adherence. BMC Health Serv Res. 2008;8:272. doi: https://doi.org/10.1186/1472-69638-272

25. Ryan RM, Deci EL. Self-Determination Theory and the Facilitation of Intrinsic Motivation, Social Development, and Well-Being. Am Psychol 2000;55(1):68-78

26. Cialdini R. B., Eisenberg N. E., Green B. L., Rhoads K., Bator R. Undermining the Undermining Effect of Reward on Sustained Interest. J Appl Soc Psychol. 1998;28(3):249-63.

27. Victor RG, Haley RW, Willett DL, Peshock RM, Vaeth PC, Leonard D et al. The Dallas Heart Study: a Population-Based Probability Sample for the Multidisciplinary Study of Ethnic Differences in Cardiovascular Health. Am J Cardiol. 2004;93(12):1473-80.

28. Victor RG, Ravenell JE, Freeman A, et al. Effectiveness of a BarberBased Intervention for Improving Hypertension Control in Black Men The barber-1 study: a Cluster Randomized Trial. Arch Intern Med. 2011;171(4):342-50.

29. Cote I, Gregoire JP, Moisan J, Chabot I. Quality of Life in Hypertension: the SF-12 Compared to the SF-36. Can J Clin Pharmacol = Journal Canadien de Pharmacologie Clinique. 2004;11(2):e232-8.

30. Fernandez S, Chaplin W, Schoenthaler AM, Ogedegbe G. Revision and Validation of the Medication Adherence Self-Efficacy Scale (MASES) in Hypertensive African Americans. J Behav Med. 2008;31(6):453-62.
31. Warren-Findlow J, Seymour RB, Brunner Huber LR. The Association Between Self-Efficacy and Hypertension Self-Care Activities Among African American Adults. J Commun Health. 2012;37(1):15-24.

32. Hibbard JH, Stockard J, Mahoney ER, Tusler M. Development of the Patient Activation Measure (PAM): Conceptualizing and Measuring Activation in Patients and Consumers. Health Serv Res. 2004;39(4 Pt 1):1005-26.

33. Crooks VC, Lubben J, Petitti DB, Little D, Chiu V. Social Network, Cognitive Function, and Dementia Incidence Among Elderly Women. Am J Public Health. 2008;98(7): 1221-7.

34. Moser A, Stuck AE, Silliman RA, Ganz PA, Clough-Gorr KM. The EightItem Modified Medical Outcomes Study Social Support Survey: Psychometric Evaluation Showed Excellent Performance. J Clin Epidemiol. 2012;65(10):1107-16.

35. Cunningham WE, Andersen RM, Katz MH, Stein MD, Turner BJ, Crystal S, et al. The Impact of Competing Subsistence Needs and Barriers on Access to Medical Care for Persons with Human Immunodeficiency Virus Receiving Care in the United States. Med Care. 1999;37(12): 1270-81.

36. The Seventh Report of the Joint National Committee on Prevention, Detection, Evaluation, and Treatment of High Blood Pressure. Bethesda, Maryland, United States Department of Health Services, National Institutes of Health, National Heart, Lung, and Blood Institute Publication No. 04-5230, 2004.

37. Tversky A, Kahneman D. Advances in Prospect Theory: Cumulative representation of Uncertainty. J Risk Uncertain. 1992;5(4):297-323.

38. American College of Cardiology/American Heart Association Task Force on Clinical Practice Guidelines. 2017 Guideline for the Prevention, Detection, Evaluation, and Management of High Blood Pressure in Adults. J Am Coll Cardiol. 2017, 23976; https://doi.org/10.1016/j. jacc.2017.07.74. Correction J Am Coll Cardiol 2018;71:e127-248.5

39. Worldwide Trends in Blood Pressure from 1975 to 2015: a Pooled Analysis of 1479 Population-Based Measurement Studies with 19.1 Million Participants. Lancet. 2017;389(10064):37-55.

40. VanEpps EM, Troxel AB, Villamil E, Saulsgiver KA, Zhu J, Chin J-Y, et al. Financial Incentives for Chronic Disease Management: Resultd and Limitations of 2 Randomized Clinical Trials With New York Medicaid Patioents. Am J Health Promot 2018;32(7):1537-43.

41. Mani A, Mullainathan S, Shafir E, Zhao J. Poverty Impedes Cognitive Function. Science 2013;341(6149):976-80.

42. Pocock SJ, Bakris G, Bhatt DL, Brar S, Fahy M, Bersh BJ. Regression to the mean in SYMPLICITY HTN-3. J Am Coll Cardiol. 2016;68(18):2016-2025.

43. Wilhelm M, Winkler A, Rief W, Doerning BK. Effect of placebo groups on blood pressure in hypertension: a meta-analysis of beta-blocker trials. J Am Soc Hypertension 2016;10(12):917-929.

44. Souza WK, Jardim PC, Brito LP, Araújo FA, Sousa AL. Self measurement of Blood Pressure for Control of Blood Pressure Levels and Adherence to Treatment. Arq Bras Cardiol. 2012;98(2):167-74.

45. Cahill K, Hartmann-Boyce J, Perera R. Incentives for smoking cessation. Cochrane Database Syst Rev. 2015;(5):CD004307.

46. Mantzari E, Vogt F, Shemilt I, Wei Y, Higgins JPT, Marteau TM. Personal financial incentives for changing habitual health-related behaviors: A systematic review and meta-analysis. Prev Med. 2015;75:75-85.

47. Thirumurthy H. Asch Da Volpp K: The uncertain effect of financial incentives to improve health behaviors. JAMA. 2019;25. https://doi.org/ 10.1001/jama.2019.2560.

48. Volpp KG, Troxel AB, Mehta SJ et al. Effect of electronic reminders, financial incentives, and social support on outcomes after myocardial infarction. JAMA Intern Med. 2017;177(8):1093-1101

49. Liu T, Volpp KG, Asch DA. The association of financial incentives for low density lipoprotein cholesterol reduction with patient activation and motivation. Prev Med Rep. 2019;14:100841. doi: https://doi.org/10. 1016/j.pmedr.2019.100841

50. Asch DA, Troxel AB, Stewart WF et al. Effect of financial incentives to physicians, patients, or both on lipid levels. A randomized trial. JAMA. 2015;314(18):1926-35

51. Sen AP, Sewell TB, Riley EB et al. Financial incentives for home-based health monitoring. A randomized trial. J Gen Intern Med. 2014; 29(5):770-7

52. Czaicki NL, Dow WH, Njau PF, McCoy SI. Do incentives undermine intrinsic motivation? Increases in motivation within an incentive-based intervention for people living with HIV in Tanzania. PLOS One. 2018. Available at: https://doi.org/10.1371/journal.pone.0196616. Accessed July 10, 2019 
53. Promberger M, Marteau TM. When do financial incentives reduce intrinsic motivation? Comparing behaviors in psychological and economic literature. Health Psychol. 2013;32(9):950-7

54. Murayama K, Matsumoto M, Izuma K, Matdsumoto K. Neural basis of the undermining effect of monetary reward on intrinsic motivation. PNAS. 2010; 107(49):20911-6

55. Shah N. Introduction. In Cohen IG, Lynch HF, Robertson CT (eds). Nudging Health: Health Law and Behavioral Economics. Baltimore, Johns Hopkins University Press 2016:187-9.

56. Underhill $\mathbf{K}$. Extrinsic incentives, intrinsic motivation, and motivational crowding out in health law and policy. In Cohen IG, Lynch HF, Robertson CT (eds). Nudging Health: Health Law and Behavioral Economics. Baltimore, Johns Hopkins University Press 2016:190-201.

57. Sen AP, Hffman D, Loewenstein G, Asch DA, Kullgren JT, Volpp KG. Do financial incentives reduce intrinsic motivation for weight loss? Underhill K. Extrinsic incentives, intrinsic motivation, and motivational crowding out in health law and policy. In Cohen IG, Lynch HF, Robertson
CT (eds). Nudging Health: Health Law and Behavioral Economics. Baltimore, Johns Hopkins University Press 2016:202-16.

58. Drawz PE, Pajewski NM, Bates JT, et al. Effect of Intensive Versus Standard Clinic-Based Hypertension Management on Ambulatory Blood Pressure: Results From the SPRINT Ambulatory Blood Pressure Study. Hypertension. 2017;69(1):42-50.

59. Victor RG, Lynch $\mathbf{K}, \mathbf{L i} \mathbf{N}$, et al. A Cluster-Randomized Trial of BloodPressure Reduction in Black Barbershops. N Engl J Med. 2018;378(14) 1291-1301.

Publisher's Note Springer Nature remains neutral with regard to jurisdictional claims in published maps and institutional affiliations. 